\title{
BMJ Open Exploration of trends in the incidence and prevalence of childhood maltreatment and domestic abuse recording in UK primary care: a retrospective cohort study using 'the health improvement network' database
}

\author{
Joht Singh Chandan (D) ,,2 Krishna Margadhamane Gokhale, ${ }^{2}$ \\ Caroline Bradbury-Jones, ${ }^{3}$ Krishnarajah Nirantharakumar, ${ }^{2}$ \\ Siddhartha Bandyopadhyay, ${ }^{4}$ Julie Taylor ${ }^{3,5}$
}

To cite: Chandan JS,

Gokhale KM, Bradbury-Jones C, et al. Exploration of trends in the incidence and prevalence of childhood maltreatment and domestic abuse recording in UK primary care: a retrospective cohort study using 'the health improvement network' database. BMJ Open 2020;10:e036949. doi:10.1136/ bmjopen-2020-036949

- Prepublication history and additional material for this paper are available online. To view these files, please visit the journal online (http://dx.doi org/10.1136/bmjopen-2020036949).

KN, SB and JT contributed equally.

Received 13 January 2020 Revised 26 March 2020 Accepted 06 May 2020

Check for updates

(c) Author(s) (or their employer(s)) 2020. Re-use permitted under CC BY-NC. No commercial re-use. See rights and permissions. Published by BMJ.

For numbered affiliations see end of article.

Correspondence to Dr Joht Singh Chandan; joht.chandan@nhs.net

\section{ABSTRACT}

Objectives Describe the epidemiology of childhood maltreatment and domestic abuse (in women).

Design Analysis of longitudinal records between 1 January 1995 to 31 December 2018.

Setting UK primary care database: 'The Health Improvement Network' (THIN).

Participants 11831850 eligible patients from 787 contributing practices. Childhood maltreatment and domestic abuse (women only) were defined as the presence of a recorded Read code.

Outcome measures The incidence rate (IR) and prevalence of childhood maltreatment (in children aged 0-18 years) and domestic abuse (in women aged over 18) between 1996 and 2017. An adjusted incidence rate ratio (aIRR) is given to examine the differences in IRs based on sex, ethnicity and deprivation.

Results The age and gender breakdown of THIN has been previously reported to be representative of the UK population, however, there is substantial missing information on deprivation quintiles $(<20 \%)$ and ethnicity (approximately $50 \%$ ). The IR (IR 60.1; 95\% Cl 54.3 to 66.0 per 100000 child years) and prevalence $(416.1 ; 95 \% \mathrm{Cl}$ 401.3 to 430.9 per 100000 child population) of childhood maltreatment rose until 2017. The alRR was greater in patients from the most deprived backgrounds (aIRR 5.14; $95 \% \mathrm{Cl} 4.57$ to 5.77 compared with least deprived) and from an ethnic minority community (eg, black alRR 1.25; 1.04 to 1.49 compared with white). When examining domestic abuse in women, in 2017, the IR was 34.5 (31.4 to 37.7$)$ per 100000 adult years and prevalence 368.7 (358.7 to 378.7) per 100000 adult population. Similarly, the IR was highest in the lowest socioeconomic class (alRR 2.30; 2.71 to 3.30) and in ethnic minorities (South Asian alRR 2.14; 1.92 to 2.39 and black alRR 1.64; 1.42 to 1.89 ). Conclusion Despite recent improvements in recording, there is still a substantial under-recording of maltreatment and abuse within UK primary care records, compared with currently existing sources of childhood maltreatment and domestic abuse data. Approaches must be implemented
Strengths and limitations of this study

- Primary care data encompass a vast proportion of society, and as current guidance is to ensure identification of domestic abuse and childhood maltreatment by general practitioners, studying the epidemiology within this dataset is important.

- Despite the vast cohort size, our results demonstrate substantial under-recording of childhood maltreatment and domestic abuse.

- Although the study was able to examine trends by age, gender, deprivation and ethnicity, trends by ethnicity were limited due to extensive missing data within UK primary care.

- Before primary care data can used as a tool for public health surveillance of childhood maltreatment and domestic abuse, there is a definite need for improved recording and/or reporting.

to improve recording and detection of childhood maltreatment and domestic abuse within medical records.

\section{INTRODUCTION}

Childhood maltreatment (physical, sexual or emotional abuse and neglect against those under the age of 18 years $)^{1}$ and domestic abuse (controlling, coercive, threatening behaviour, violence or abuse between those who are, or have been, intimate partners or family members $)^{2}$ are global public health problems. The negative downstream social, psychological and physical health effects of childhood maltreatment and domestic abuse bear a substantial societal cost. ${ }^{3-12}$ Therefore, a public health approach is urgently needed to prevent both the occurrence of childhood maltreatment and domestic abuse as well 
as their secondary consequences. ${ }^{13}$ In order to support a public health approach, high quality data recording relating to these exposures plays an important role. ${ }^{13}$ Exploring the role of routinely collected data (which due its repeatable nature can be used for surveillance) in the UK as well as other countries is crucial in both the estimation of the societal burden of disease as well as the identification of risk and protective factors. ${ }^{14}$

Exposure to domestic abuse and childhood maltreatment remain taboo topics in many cultures, despite the adverse consequences in terms of health and well-being, with significant stigma around disclosure of traumatic events. ${ }^{1516}$ As a result, survivors of such traumatic experiences often find it difficult to attend and seek support from public sector authorities such as healthcare staff. ${ }^{17} 18$ There are also challenges for healthcare staff to routinely enquire or ask about such experiences in their patients' lives. ${ }^{19}$ The combination of barriers to disclosure and enquiry are likely to lead to a hidden burden of domestic abuse and childhood maltreatment not captured in administrative public sector data. However, since introductions of new guidelines in the UK (National Institute of Health and Care Excellence in 2016 and 2017), the hope has been that administrative recording will have improved..$^{20}{ }^{21}$ This drive towards improved reporting is spurred on by UK media and governmental interest in these topics (high profile events leading to media and governmental interest include: the death of Baby $\mathrm{P}$, the Jimmy Savile inquiry, Operation Yewtree, the death of Daniel Pelka, the identification and referral to improve safety trial and the consideration of the domestic abuse bill), and the consequent expectation that administrative recording will have improved. ${ }^{22-26}$

Current UK national estimates of domestic abuse are largely derived from self-reported surveys in conjunction with administrative data. The crime survey for England and Wales (CSEW) provides self-reported information and used in conjunction with police records of the number of recorded domestic abuse incidents to define epidemiological estimates of domestic abuse. In women, the reported prevalence from the CSEW (for those aged 16-59 years old) was $7.9 \%$ in the financial year $2017 / 2018$ while the crude estimate derived from police data for the year ending 2017 (not yet available for 2018 for those aged 16 and over) across England was 24.0/1000 population (in men and women). ${ }^{27} 28$

Unfortunately, the use of alternative administrative records pertaining to information on domestic abuse are limited to recording processes such as hospital records. There is no specific international classification of disease code that are specific to domestic abuse: The closest matches are T74.1 (physical abuse, confirmed), Y07.0 (spouse or partner, perpetrator of maltreatment and neglect) and Z63.0 (and problems in a relationship with spouse or partner) which when specified in adults relate to physical abuse, maltreatment. ${ }^{29}$ However, there are substantial limitations to utilising these codes to describe the epidemiology of domestic abuse, due to low numbers of such codes being recorded and also ambiguities in coding practice between hospital trusts. ${ }^{29}$

The state of epidemiological estimates when exploring childhood maltreatment suffers from similar challenges. A recent observational study used data from 1858 to 2016 that was derived from child mortality records, police recorded-homicides, crimes against children, child protection data, children in care and data taken from the National Society for the Prevention of Cruelty to Children (NSPCC) to study long term trends of child maltreatment. The study found a decreasing long-term trend in child maltreatment until the year 2000 but reported an increase thereafter. ${ }^{30}$ However, child mortality continued to decrease..$^{30} \mathrm{~A}$ recommendation of the report was to further research and establish whether child maltreatment is continuing to increase. ${ }^{30}$ However, once again when taken from the CSEW, the estimated prevalence of experiencing childhood maltreatment was $18.9 \%$ (financial year end 2016). ${ }^{31}$ The information relating to the incidence rate (IR) for those at risk of childhood maltreatment or domestic abuse is low. One approach to attempt to do so is to use records taken from general practice (GP). A previous study using GP recorded data between 1995 and 2010 explored the IRs and prevalence of childhood maltreatment-related concerns (includes information relating to suspected and possible maltreatment) and identified an increase in incidence and prevalence of maltreatment related concerns between this time. ${ }^{32}$

In summary, the limitations of existing estimates relate to challenges with: (1) continuous recording of survey data to allow for active surveillance and examination of trends; (2) social desirability bias ${ }^{33}$ leading to an underestimation in survey estimates; (3) selection bias ${ }^{34}$ leading to an under-estimation in administrative datasets and (4) an appropriate denominator population to describe prevalence in administrative data.

Primary care data from sources such as 'The Health Improvement Network' (THIN) database have previously been shown to representative of the UK population in terms of age structure and can provide a suitable denominator population to examine the epidemiology of public health risk factors. ${ }^{35}$ Additionally, new guidelines and interventions have been put in place to improve recording of childhood maltreatment and domestic abuse. ${ }^{20} 212636$ The last time primary care data were explored to describe a similar risk factor was in 2010 prior to these improvements. Therefore, there is a need to describe the current estimates of childhood maltreatment and domestic abuse from primary care data and compare these to existing estimates to describe the possibility of further use of primary care data to support policy-makers/public health professionals in decisions relating to the burden of maltreatment and abuse.

Our aim was to investigate how the incidence and prevalence of childhood maltreatment and domestic abuse have changed between 1996-2017 using THIN primary care database. 


\section{METHODS}

\section{Study design and data source}

A cohort was extracted of eligible patients who contributed to the dataset between 1 January 1995 and 31 December 2018. Using this cohort, it was possible to describe the yearly IR and prevalence of childhood maltreatment and domestic abuse. Using the cohort it was also possible to describe the cumulative IR broken down by age group, gender (in childhood maltreatment), deprivation and ethnicity.

During the study period, the dataset consisted of medical records taken from 787 UK GPs and deemed to be representative of the UK population. ${ }^{35}$ THIN records information relating to demographics, disease progression and management. ${ }^{37}$ Information relating to symptoms, examinations and diagnoses is documented using a hierarchical clinical coding system called Read codes. ${ }^{38}$

\section{Population, exposure and outcomes}

GPs were eligible for inclusion 12 months following installation of electronic health records or from the practice's acceptable mortality recording date. ${ }^{39}{ }^{40}$ Inclusion of data after these points were measures of quality assurance for the dataset. During the study period from 1 January 1995 and 31 December 2018, there were 11831850 eligible patient records following this inclusion criteria.

The outcomes of interest (childhood maltreatment or domestic abuse) were both defined by presence of a relevant Read code relating to patient exposure. As the aim of this study was to examine incidence and prevalence, the code list used to define incidence and prevalence varied to account for codes that mention a history of the exposure (for the calculation of prevalence but not for IR). The list of Read codes used in this study to describe childhood maltreatment/domestic abuse (varied by incidence and prevalence) are documented in the online supplementary (supplementary read code lists) and selection of such codes are described in previous published work. ${ }^{791041}$ Domestic abuse exposure in this study was limited to only female patients as comparatively very low numbers of men had recorded incidents of domestic abuse during the study period (displayed in table 1). The annual IR and prevalence of domestic abuse experienced by men between 2005 and 2017 is displayed on online supplementary tables 1 and 2.

Dependent on the outcome of interest, there were further inclusion criteria on the study population which were eligible for inclusion. To calculate the IR and prevalence of childhood maltreatment, we only included patients under the age of 18 at cohort entry. We enforced a study criterion that patients would have to exit the study by their 18th birthday as they would no longer be contributing child-years (CY) at risk. During the study period, the total population amounted to 3045456 children. In order to calculate the IR and prevalence of domestic abuse, a female adult cohort was selected who had an eligible cohort entry date from the age of 18 years onwards (4982781 eligible patients). The purpose being to allow us to calculate an IR of adult years (AY) at risk. Additionally, there is debate about whether children living in a household where there is domestic abuse overlaps with the definition of child maltreatment as a form of adverse childhood experience (ACEs). ${ }^{42}$ Therefore, to avoid confusion in definition between childhood maltreatment and experiencing ACEs which include other markers of household adversity, we have restricted our domestic abuse population to only those over the age of 18 years.

\section{Statistical analysis and follow up}

For annual point prevalence, the numerator was the cumulative count of eligible individuals with any record of domestic abuse (occurred over 18 years) or childhood maltreatment (occurred under 18 years) identified at the 1 January each year from 1996 to 2017 who were then divided by the total eligible population on the same date (denominator). The prevalence is described per 100000 population (in the domestic abuse cohort per 100000 adult population and childhood maltreatment cohort per 100000 child population) with their associated CIs.

A series of yearly cohort studies were performed to calculate the crude IR of domestic abuse and childhood maltreatment for each year from 1996 to 2017. The numerator was the new number of cases in that calendar year, divided by the total number of person-years at risk (denominator) for the given year. In each annual cohort study to determine IR, the period of follow-up was defined as:

Entry date: The latest date of either study start date (1 of January each year), 1 year after electronic medical records were implemented, 1 year after the practice reached acceptable mortality recording date or when the patient met the age inclusion criteria if one was present (eg, patients had to reach 18 years before they were eligible for entry into the domestic abuse study population).

Exit date: The earliest date of either study end date (31 of December each year), outcome date (new incident of childhood maltreatment or domestic abuse), death date, transfer date (when patient moved practice and were censored from the dataset), collection date (last date the practice contributed to the dataset) and the date when patient's age crosses the age inclusion criteria (eg, patients will exit the cohort when they turn 18 for the IR calculation of childhood maltreatment).

Graphical representations of the incidence and prevalence was conducted from years where there were five or more incident cases of domestic abuse (2005) or childhood maltreatment (1997). The annual IR and prevalence are also stratified by sex (male or female) for childhood maltreatment.

Additionally, the cumulative IR for the whole time period from the 1 January 1995 to 31 December 2018 was stratified by age category of outcome incidence (defined using categories used by the Department of Education to allow for comparison),${ }^{43}$ Townsend deprivation quintile, ${ }^{44}$ ethnicity and sex when using data for the whole 
time period from the f1 January 1995 to 31 December 2018.

To discern differences between ethnic groups and deprivation quintiles (in the child cohort) a multivariate (adjusting for each other, sex and age at cohort entry) Poisson regression offsetting for person years of follow-up was used to calculate an adjusted incidence rate ratio (aIRR). Where there were missing data in our covariates (Ethnicity and Townsend quintile), these were treated as a separate missing category and included in the final model. Significance was set at $\mathrm{p}<0.05$.

Statistical analysis was conducted using STATA MP/4V.15.1 (Statacorp 2017). Wherever IR, IRR and prevalence are presented, associated 95\% CIs are given in conjunction.

\section{Patient and public involvement}

No patients were actively involved in setting the research question, outcome measures, study design, results interpretation of write up of the results. There are plans for the results to be disseminated to the community affected by this research through childhood maltreatment and domestic abuse charities and social media channels.

\section{RESULTS}

During the study period, there was a total of 4603 incident episodes of childhood maltreatment cohort in a cohort of 3045456 children (aged under 18). In the adult female cohort (aged over 18), there were 5598 incident recorded episodes of domestic abuse in the total female population of 4982781 patients. Table 1 outlines the characteristics of both cohorts at cohort entry as well as the patients who were incident cases of childhood maltreatment and domestic abuse.

\section{Childhood maltreatment}

The IR of childhood maltreatment increased from 22.5 per $100000 \mathrm{CY}$ (95\% CI 11.8 to 33.2) in 1997 to 60.1 per $100000 \mathrm{CY}(95 \%$ CI 54.3 to 66.0) in 2017. The was a steadily increasing trend from 2007 to 2012 and a steep rise between the year 2012 (IR 30.0; 95\% CI 26.8 to 33.3 per $100000 \mathrm{CY}$ ) and 2013 (IR 52.3; 95\% CI 47.9 to 56.7 per $100000 \mathrm{CY}$ ), after which it remained relatively stable until 2017. Further details can be seen in figure 1A and online supplementary table 3 .

When broken down by sex, a similar temporal trend is noted between both males and females. However, the cumulative IR was higher in the female cohort (IR 27.2; $95 \% \mathrm{CI} 26.1$ to 18.6 per $100000 \mathrm{CY}$ ) was greater when compared with the male cohort (IR 19.4; $95 \%$ CI 18.6 to 20.3 per $100000 \mathrm{CY}$ ). The IR in females in 2017 was 66.2 (95\% CI 57.4 to 75.1 ) per 100000 CY compared with IR of 54.3 (95\% CI 46.5 to 62.1) per $100000 \mathrm{CY}$ in males. Further details of the trends are seen on figure 1B,C and online supplementary tables 4 and 5 .

The age range was broken down into the categories $0-1,1-4,5-9,10-15$ and $16-17$ years. The group with the highest IR was the $0-1$ year cohort (IR 52.7; 95\% CI 47.9 to 58.0 per $100000 \mathrm{CY}$ ) and whereas the $16-17$ group (IR 21.2; 95\% CI 19.0 to 23.5 per $100000 \mathrm{CY}$ ) had the lowest IR (figure 1D and online supplementary table 6 ). When examining by socioeconomic deprivation quintile there was a linear relationship observed between IR and deprivation. More details are seen in figure $1 \mathrm{E}$ and online supplementary table 7. Lastly, the IR was higher in the ethnic minority groups (black (IR 45.1; 95\% CI 37.4 to 52.9 per 100,000 CY), South Asian (IR 34.7; 95\% CI 29.0 to 40.4 per 100,000 CY) and other backgrounds (IR 48.1; 95\% CI 37.3 to 58.9 per 100,000 CY)) when compared with those who had a white (IR 27.7; $95 \%$ CI 26.5 to 29.0 per 100,000 CY)) or mixed ethnicity (IR 21.8; 95\% CI 13.4 to 30.2 per 100,000 CY). Further details are provided in figure $1 \mathrm{~F}$ and online supplementary table 8 .

The prevalence of childhood maltreatment steadily increased from 176.3 (95\% CI 132.8 to 219.8) per 100000 child population in 1997 to 416.1 (95\% CI 401.3 to 430.9$)$ per 100000 population in 2017. This can be seen in figure 2 and online supplementary table 9 .

In the multivariate analysis following adjustment for age at cohort entry, sex and deprivation quintile, the increased risk apparent in South Asians compared with white children was not evident (aIRR 1.06; 95\% CI 0.89 to 1.26). However, the black (aIRR 1.25; 95\% CI 1.04 to 1.49 ) and other (aIRR 1.45; 95\% CI 1.15 to 1.82 ) populations were at a greater risk. In the above analysis, there was a gradient increase observed in the risk of childhood maltreatment with worsening deprivation. The most deprived quintile had a fivefold increased risk of childhood maltreatment (aIRR 5.14; 95\% CI 4.57 to 5.77). Further details are seen in online supplementary table 10 .

\section{Domestic abuse}

The IR of domestic abuse increased from 0.3 per 100000 AY (95\% CI 0.0 to 0.6 ) in 2005 to 34.6 per $100000 \mathrm{AY}$ (95\% CI 31.4.1 to 37.7) in 2017. The trend was increasing relatively steadily from 2006 to 2013 , followed by a steep increase in 2014 (IR 35.8; 95\% CI 33.2 to 38.5 per 100000 $\mathrm{AY})$. Further details can be seen in figure $3 \mathrm{~A}$ and online supplementary table 11.

The age range was broken down into the categories $18-24,25-34,35-44,45-54,55-64$ and over 65 years. The groups with the highest IR were 18-24 (IR 33.0; 95\% CI 31.2 to 34.9 per $100000 \mathrm{AY}$ ) and 25-34year cohorts (IR 33.7; 95\% CI 32.2 to 35.3 per $100000 \mathrm{AY}$ ), followed by a decline by age group. Further details are seen in figure 3B and online supplementary table 12 . When examining by deprivation quintile, again a linear trend was seen where there was a fourfold increased risk of new domestic abuse incidence in the most deprived quintile (IR 36.3; 95\% CI 34.3 to 38.3 per $100000 \mathrm{AY}$ ) compared with the least deprived (IR 8.9; $95 \%$ CI 8.2 to 9.6 per $100000 \mathrm{AY}$ ). More information can be found in figure $3 \mathrm{C}$ and online supplementary table 13. Lastly, similar to childhood 
A

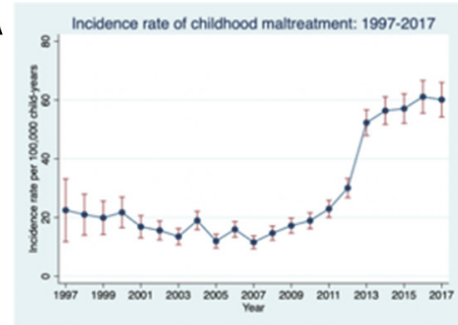

D

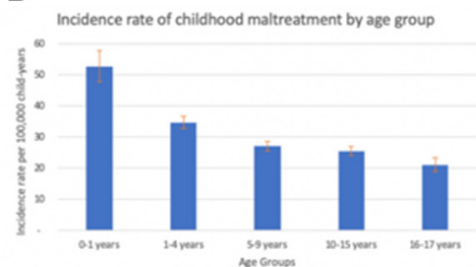

B

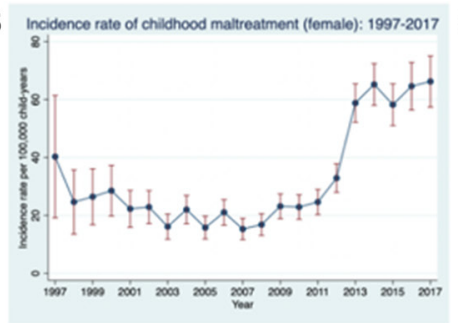

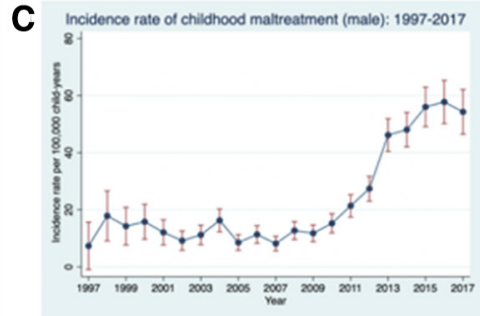

E

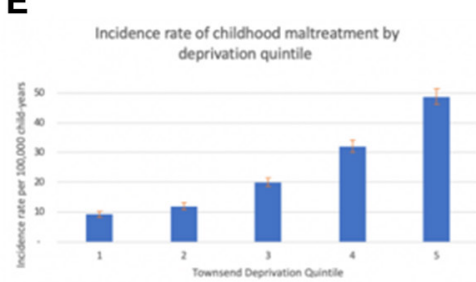

$\mathbf{F}$

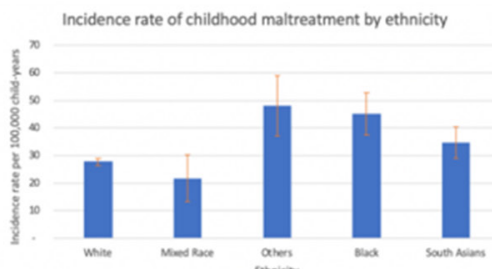

Figure 1 The incidence rate of childhood maltreatment broken down by sex, age, deprivation and ethnicity.

maltreatment, a disparity was seen in relation to ethnic group, where black (IR 55.0; 95\% CI 47.7 to 62.6 per $100000 \mathrm{AY}$ ), South Asian (IR 65.4; $95 \%$ CI 58.6 to 72.2 per $100000 \mathrm{AY}$ ) and other background (IR 73.6; 95\% CI 57.4 to 89.7 per $100000 \mathrm{AY}$ ) had a higher IR when compared with those who had a white (IR 21.5; 95\% CI 20.7 to 22.3 per $100000 \mathrm{AY}$ ) or mixed ethnic (IR 36.8; $95 \%$ CI 29.4 to 44.2 per $100000 \mathrm{AY}$ ) background. Figure 3D and online supplementary table 14 contain additional detail.

The prevalence of domestic abuse increased in an almost linear manner from 16.0 (95\% CI 14.0 to 17.9 ) per 100000 adult population to 368.7 (95\% CI 358.7 to $378.9)$ per 100000 adult population in 2017. This can be seen in figure 4 and from online supplementary table 15 .

In the multivariate regression analysis, it was evident that ethnicity played a factor in the risk of domestic abuse. South Asians (aIRR 2.14; $95 \%$ CI 1.92 to 2.39), black (aIRR 1.64; 95\% CI 1.42 to 1.89 ) and other (aIRR 2.19; 95\% CI 1.75 to 2.73 ) populations were all at a greater risk than the White cohort. Similar to childhood maltreatment there was a gradient increase between worsening deprivation and the risk of domestic abuse. The most deprived quintile had an aIRR of 2.30; 95\% CI 2.71 to 3.30. Further details contained within online supplementary table 16 .

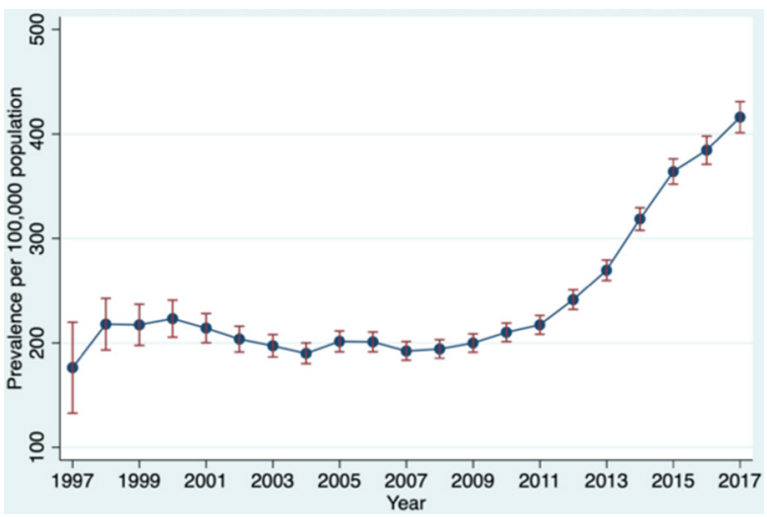

Figure 2 Prevalence of childhood maltreatment: 1997-2017.

\section{DISCUSSION}

\section{Summary of key findings}

The IR of both childhood maltreatment and domestic abuse increased until 2017 (60.1;95\% CI 54.3 to 66.0) per $100000 \mathrm{CY}$ and 34.6 (95\% CI 31.4.1 to 37.7) per 100000 AY, respectively, in 2017). Additionally, the prevalence of both childhood maltreatment and domestic abuse continued to increase in a linear fashion until 2017. Of interest there were similar patterns of risk in both groups. For both childhood maltreatment and domestic abuse, there was a substantially increased aIRR seen in those from a more deprived background when compared with the least deprived, and a greater IR of new cases of both childhood maltreatment and domestic abuse in those from an ethnic minority background despite taking into account other co-variates. The IR was also highest in the 0-1 year group and in females for childhood maltreatment and the 18-24years group for those experiencing domestic abuse. The most notable finding is the high level of under-recording of childhood maltreatment and domestic abuse in the dataset in comparison to those reported in self-reported surveys including the CSEW and NSPCC survey.

\section{Comparison to current literature}

As this was the first cohort to the authors' knowledge to explore the annual incidence and prevalence of domestic abuse (in women) using UK primary care records, it is difficult to compare the IRs directly with other studies. However, for childhood maltreatment, one previous study (including data from 1995 to 2010) reported the IR of childhood maltreatment related concerns using THIN. ${ }^{32}$ The maltreatment-related concern codes included cases of suspected or probable maltreatment which would explain why their documented IR and prevalence are substantially higher than those reported in our study. ${ }^{32}$ However, of note in that study they demonstrated an increased IR of childhood maltreatment related concerns in those in the under one group, those who are female 
A

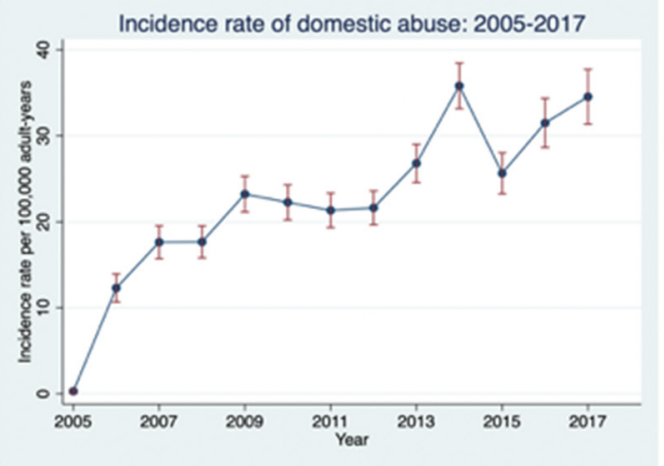

C

Incidence rate of domestic abuse by deprivation quintile

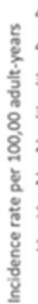

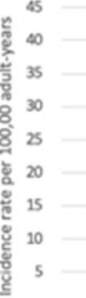

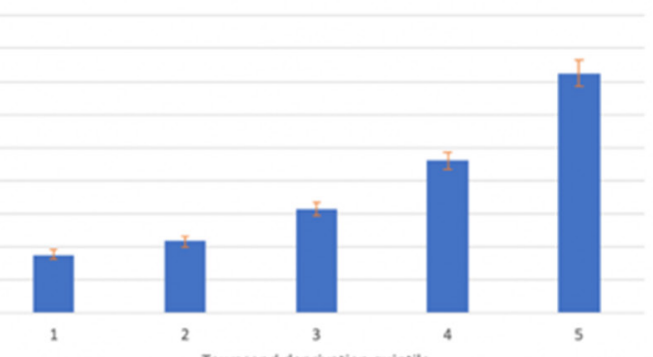

B

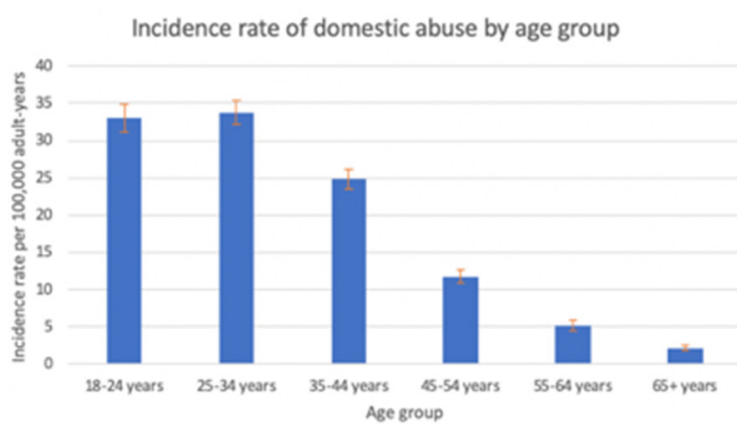

D

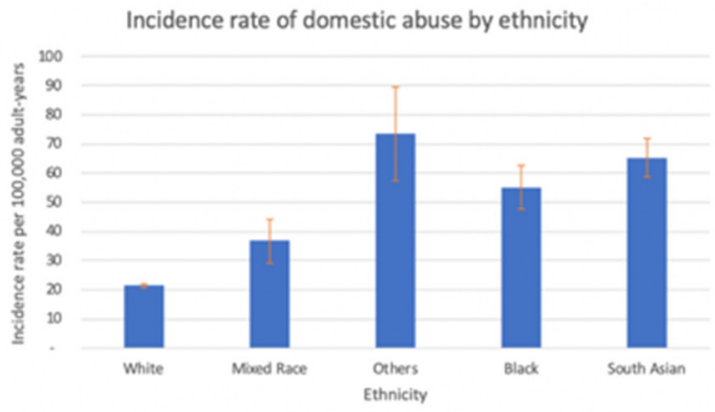

Figure 3 The incidence rate of domestic abuse broken down by age, deprivation and ethnicity.

and almost a five times increased risk in those from the most deprived group when compared with the lowest group, all of which are similar to our findings. ${ }^{32}$

Of particular note, a key finding of our study was the prevalence and IR were much lower than estimates derived from currently existing sources of childhood maltreatment and domestic abuse epidemiology. When examining UK police reports of domestic abuse, although for both genders, the prevalence in England was 24.0 per 1000 population, much higher than in our study even though we only included a female denominator population. ${ }^{27}$ When compared with the CSEW data which showed a prevalence of $7.9 \%$ in women, our figure seems even lower. ${ }^{28}$ Similarly, although no combined child maltreatment figure exists for police reports, if we examine the estimated prevalence from the CSEW which

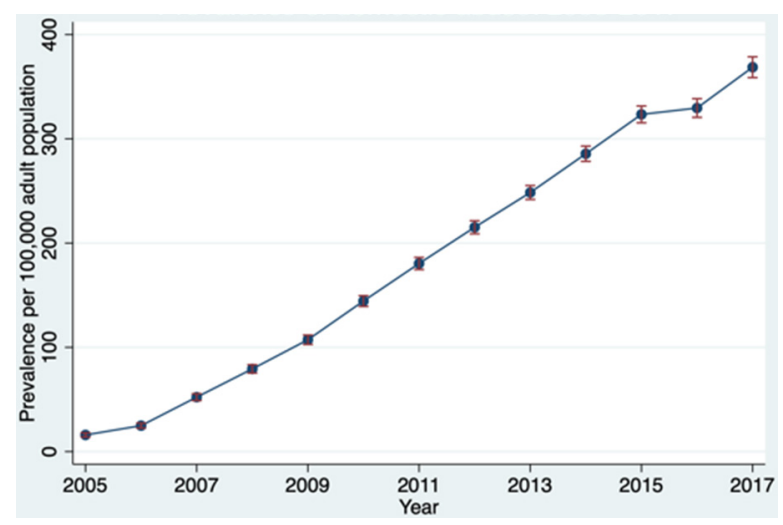

Figure 4 Prevalence of domestic abuse: 2005-2017. suggested $18.9 \%$ of all adults have experienced some form of childhood maltreatment our figure of 4.2 per 1000 population (2017) is substantially lower. ${ }^{31}$ When compared with other administrative data such as children in need data, which contains the rate of children on Child protection plans, GP recorded prevalence still remains low, which has also been shown in previous literature on maltreatment-related concerns. ${ }^{3245}$

The low values of incidence and prevalence of childhood maltreatment and domestic abuse and other interesting findings resonate and build on known literature. There have been national policy reports highlighting inconsistencies in data collected relating domestic abuse and childhood maltreatment to poverty and ethnicity. ${ }^{467}$ However, we clearly demonstrate a linear relationship between IR and socioeconomic deprivation following adjustment for ethnicity. When adjusting for deprivation, GP data still highlights the burden of maltreatment and abuse experienced in ethnic minorities (although South Asians were not at a higher risk of childhood maltreatment, and mixed raced individuals were not at a higher risk of either childhood maltreatment or domestic abuse). It has been previously highlighted that black and minority ethnic children are over-represented in child protection records within the UK, but this may be related to poverty (a form of which we have been able to adjust for in our study), isolation and willingness to seek help due to stigma in some communities. ${ }^{48}$ In contrast to our findings, the prevalence reported for domestic abuse exposure CSEW was highest in those from a mixed race 
background, and lower in those from the South Asian, black or other community. ${ }^{28}$

There are clear messages that need to be taken from this study relating to the under-recording of domestic abuse and childhood maltreatment in GP records. Although approaches and intervention have been implemented and evaluated to record both of these traumatic experiences, more needs to be done. ${ }^{26}{ }^{36}$ Healthcare professionals should be aware of the morbidity burden caused by such exposures and also the referral tools at their disposal highlighted in recent national guidelines. ${ }^{2021}$ Attempts to overcome barriers in asking about domestic abuse and childhood maltreatment such as the use of short question proformas are options to be trialled more broadly. ${ }^{49}$ Although recording of domestic abuse and childhood maltreatment do not yet fall under the incentivised payment system for GPs, it should be strongly encouraged to improve our recording and implementation of appropriate referral mechanisms. ${ }^{50}$ Although this study was unable to explore the reasons for underrecording by GPs, there is substantial literature on reasons for the under-recording and under-reporting of maltreatment and abuse summarised in a recent review. ${ }^{51}$ Factors refer to either challenges in the recognition or reporting of maltreatment and abuse. Variables which may affect recognition include experience and knowledge levels of the treating clinician or variation in the threshold between clinicians as to what is reasonable suspicion of maltreatment or abuse. ${ }^{51}{ }^{52}$ Additionally, factors which affect the clinician reporting the maltreatment or abuse include: (1) knowledge of the family; (2) expected negative outcomes of reporting to child-protection services; (3) lack of confidence that reporting would improve patient outcomes and (4) damage to the patient-clinician relationship. ${ }^{51}$ Therefore, education approaches going beyond data improvement and screening are needed to improve not only recognition but reporting practices.

\section{Strengths and limitations}

Although our data are derived from a large populationbased cohort, the results demonstrate substantial underrecording of childhood maltreatment and domestic abuse. Therefore, our results are likely to underestimate the burden of childhood maltreatment and domestic abuse by GPs. The increasing trends in IR and prevalence suggest that recording is improving and with the introduction of national guidelines and standards, this will continue to improve. ${ }^{2021}$ Before this dataset can be used for surveillance purposes or tracking of long term trends in childhood maltreatment or domestic abuse, there need to be further improvements in the rate or recording and reporting. Although this study was not designed to assess the impact of public policy or media attention at certain time points, it is also possible that spikes in IR seen in the dataset such as in 2012-2013 in the childhood maltreatment cohort may be related to high profile news events such as the exposure of Jimmy Savile which was shown to result in an increase of reports of childhood maltreatment to UK statutory bodies..$^{53}$ Additionally, as time progress, it may be possible to conduct an interrupted time series analysis to assess the impact of changes in the NICE guidance and whether this has led to improved recording and reporting.

It is also important to note that the reliability of the findings are largely reliant on the accuracy of the coding practices by the GP. As seen in this study, there are a wide variety of codes relating to childhood maltreatment and domestic abuse. It is possible that information relating to maltreatment and abuse is included in the free-text narrative during clinical consultation which is not accessible. Therefore, we advise that in future studies, that where possible, free-text analysis is conducted on clinical records to assess if this increases the number of reported cases.

In our IR subgroup analysis, we also have limitations in the recorded ethnicity of patients (highlighted in table 1). Ethnicity recording has historically been poor, although improving in primary care data, with missing rates of around $50 \% .^{54}$ Therefore, future research should aim to explore the IR of these outcomes in other cohorts which have utilised similar UK census categories for ethnicity. Another approach in future analyses is if the dataset provides information on linked family members, it may be possible to infer the ethnicity if missing data are present.

\section{CONCLUSION}

In conclusion, our study showed an in-depth exploration of the IR and prevalence trends of childhood maltreatment and domestic abuse using UK primary care records. It is clear that there is a severe under-reporting of both of these important exposures which relate to substantial morbidity and mortality burdens. Therefore, approaches to improve recording of abuse and strategies to detect and prevent negative consequences of childhood maltreatment and domestic abuse should be implemented.

\section{Author affiliations}

${ }^{1}$ University of Warwick Warwick Medical School, Coventry, UK

${ }^{2}$ Institute of Applied Health Research, University of Birmingham College of Medical and Dental Sciences, Birmingham, UK

${ }^{3}$ School of Nursing, College of Medical and Dental Sciences, University of Birmingham, Birmingham, UK

${ }^{4}$ The Department of Economics, University of Birmingham, Birmingham, UK ${ }^{5}$ Birmingham Women's and Children's NHS Foundation Trust, Birmingham, UK

Twitter Joht Singh Chandan @johtchandan, Krishna Margadhamane Gokhale @krishnagokhale, Caroline Bradbury-Jones @jones_bradbury, Krishnarajah Nirantharakumar@nirantharakumar, Siddhartha Bandyopadhyay @sbandyo72 and Julie Taylor @bulawayojulie

Acknowledgements The study team would like to thank Ms Anuradhaa Subramanian for her support with the statistical analysis. The team would also like to thank the University of Birmingham for supporting the open access fees.

Contributors This study contributed to the $\mathrm{PhD}$ thesis for the main author JSC. JSC, JT, SB and KN were responsible for initial conception of the study. JSC and KG were responsible for data extraction, analysis and first draft of the manuscript. All authors were then involved in critical discussion of the draft. The final manuscript was authorised by all the authors with JT providing expert knowledge on childhood 
maltreatment, C-BJ provided expertise on domestic abuse whereas SB and KN provided methodological expertise. All authors agree to be accountable for all aspects of the work.

Funding The authors have not declared a specific grant for this research from any funding agency in the public, commercial or not-for-profit sectors.

\section{Competing interests None declared.}

Patient and public involvement Patients and/or the public were not involved in the design, or conduct, or reporting, or dissemination plans of this research.

\section{Patient consent for publication Not required.}

Ethics approval Anonymised data were used throughout the study provided by the data provider to the University of Birmingham. Studies using The Health Improvement Network (THIN) database have had initial ethical approval from the NHS South-East Multicentre Research Ethics Committee, subject to prior independent scientific review. The Scientific Review Committee (IQVIA) approved the study protocol (SRC Reference Number: SRC18THIN034) prior to its undertaking.

Provenance and peer review Not commissioned; externally peer reviewed.

Data availability statement Data are available on reasonable request. The original data can be requested from the study team. However, ethics approval may need to be sought from the data provider prior to release of data.

Open access This is an open access article distributed in accordance with the Creative Commons Attribution Non Commercial (CC BY-NC 4.0) license, which permits others to distribute, remix, adapt, build upon this work non-commercially, and license their derivative works on different terms, provided the original work is properly cited, appropriate credit is given, any changes made indicated, and the use is non-commercial. See: http://creativecommons.org/licenses/by-nc/4.0/.

ORCID iD

Joht Singh Chandan http://orcid.org/0000-0002-9561-5141

\section{REFERENCES}

1 HM Government. Working together to safeguard children: a guide to inter-agency working to safeguard and promote the welfare of children, 2018. Available: https://assets.publishing.service.gov.uk/ government/uploads/system/uploads/attachment_data/file/722305/ Working_Together_to_Safeguard_Children_-_Guide.pdf

2 HM Government. Guidance: domestic violence and abuse, 2016. Available: https://www.gov.uk/guidance/domestic-violence-andabuse\#domestic-violence-and-abuse-new-definition

3 Bellis MA, Hughes K, Ford K, et al. Life course health consequences and associated annual costs of adverse childhood experiences across Europe and North America: a systematic review and metaanalysis. Lancet Public Health 2019;4:e517-28.

4 Gilbert R, Widom CS, Browne K, et al. Burden and consequences of child maltreatment in high-income countries. Lancet 2009;373:68-81.

5 Bacchus LJ, Ranganathan M, Watts C, et al. Recent intimate partner violence against women and health: a systematic review and metaanalysis of cohort studies. BMJ Open 2018;8:e019995.

6 Krug EG, Dahlberg LL, Mercy JA, et al. World report on violence and health. Available: http://apps.who.int/iris/bitstream/handle/10665/ 42495/9241545615_eng.pdf;jsessionid=38974668595BA31895E5 57DC1CB1EFEC? sequence $=1$

7 Chandan JS, Thomas T, Bradbury-Jones C, et al. Female survivors of intimate partner violence and risk of depression, anxiety and serious mental illness. Br J Psychiatry 2019:1-6.

8 Chandan JS, Thomas T, Raza K, et al. Intimate partner violence and the risk of developing fibromyalgia and chronic fatigue syndrome. $J$ Interpers Violence 2019;088626051988851:088626051988851.

9 Chandan JS, Thomas T, Gokhale KM, et al. The burden of mental ill health associated with childhood maltreatment in the UK, using the health improvement network database: a population-based retrospective cohort study. Lancet Psychiatry 2019:6:926-34.

10 Chandan JS, Thomas T, Bradbury-Jones C, et al. Intimate partner violence and temporomandibular joint disorder. J Dent 2019;82:98-100.

11 Chandan JS, Thomas T, Bradbury-Jones C, et al. Risk of cardiometabolic disease and all-cause mortality in female survivors of domestic abuse. J Am Heart Assoc 2020;9:e014580.

12 Chandan JS, Okoth K, Gokhale KM, et al. Increased cardiometabolic and mortality risk following childhood maltreatment in the United Kingdom. J Am Heart Assoc 2020;9:e015855.
13 Chandan JS, Taylor J, Bradbury-Jones C, et al. COVID-19: a public health approach to manage domestic violence is needed. Lancet Public Health 2020. doi:10.1016/S2468-2667(20)30112-2. [Epub ahead of print: 08 May 2020].

14 World Health Organization. The public health approach, 2011. Available: http://www.who.int/violenceprevention/approach/public_ health/en/

15 Overstreet NM, Quinn DM. The intimate partner violence stigmatization model and barriers to help-seeking. Basic App/ Soc Psych 2013;35:109-22.

16 Allnock D, Miller P. No one noticed no one heard report, 2013. Available: https://pdfs.semanticscholar.org/7258/5fbe2269c865ac7c 42aaf0e4bec5224a938b.pdf

17 Smith CS. Coping strategies of female victims of child abuse in treatment for substance abuse relapse: their advice to other women and healthcare professionals. $J$ Addict Nurs 2007;18:75-80.

18 Robinson L, Spilsbury K. Systematic review of the perceptions and experiences of accessing health services by adult victims of domestic violence. Health Soc Care Community 2007:16:16-30.

19 Taket A. Responding to domestic violence in primary care. BMJ 2012;344:e757.

20 NICE. Child abuse and neglect, 2017. Available: https://www.nice. org.uk/guidance/ng76 [Accessed 16 Dec 2019].

21 NICE. Domestic violence and abuse, 2016. Available: https://www. nice.org.uk/guidance/qs116

22 Parish E. Who should we blame for the death of baby P? BMJ 2014;349:96643.

23 Staffordshire \& stoke-on-trent safeguarding children boards. lessons to be learned briefing no. 16: in respect of the death of daniel pelka, 2013. Available: https://www.staffordbc.gov.uk/sites/default/files/ cme/DocMan1/PolicyAndlmprovement/Serious-Case-Review-DanielPelka.pdf [Accessed 16 Dec 2019].

24 Department for Education. Investigations relating to Jimmy Savile - GOV.UK, 2015. Available: https://www.gov.uk/government/ publications/investigations-relating-to-jimmy-savile [Accessed 16 Dec 2019].

25 UK Parliament. Domestic abuse bill 2017-19, 2017. Available: https:// services.parliament.uk/bills/2017-19/domesticabuse.html

26 Feder G, Davies RA, Baird K, et al. Identification and referral to improve safety (iris) of women experiencing domestic violence with a primary care training and support programme: a cluster randomised controlled trial. Lancet 2011;378:1788-95.

27 Public health England. Public health profiles domestic abuse, 2018. Available: https://fingertips. phe.org.uk/search/Domestic Abuse\#page/4/gid/1/pat/6/par/E12000004/ati/102/are/E06000015/ iid/92863/age/164/sex/4 [Accessed 16 Dec 2019].

28 Office for national statistics. Domestic abuse in England and Wales: year ending March 2018, 2018. Available: https://www.ons.gov.uk/ peoplepopulationandcommunity/crimeandjustice/bulletins/dome sticabuseinenglandandwales/yearendingmarch2018\#prevalence-ofdomestic-abuse

29 Olive P. Intimate partner violence and clinical coding: issues with the use of the International classification of disease (ICD-10) in England. $J$ Health Serv Res Policy 2018;23:212-21.

30 Degli Esposti M, Humphreys DK, Jenkins BM, et al. Long-Term trends in child maltreatment in England and Wales, 1858-2016: an observational, time-series analysis. Lancet Public Health 2019:4: e148-58.

31 Office for National Statistics. Abuse during childhood, 2016. Available: https://www.ons.gov.uk/peoplepopulationandcommunity/ crimeandjustice/articles/abuseduringchildhood/findingsfromtheyeare ndingmarch2016crimesurveyforenglandandwales

32 Woodman J, Freemantle N, Allister J, et al. Variation in recorded child maltreatment concerns in UK primary care records: a cohort study using the health improvement network (thin) database. PLoS One 2012;7:e49808.

33 Grimm P, Bias SD. Social Desirability Bias. In: Wiley international encyclopedia of marketing. Chichester, UK: John Wiley \& Sons, Ltd, 2010.

34 Drake B, Jonson-Reid M, Kim H. Surveillance bias in child maltreatment: a Tempest in a teapot. Int J Environ Res Public Health 2017;14. doi:10.3390/ijerph14090971. [Epub ahead of print: 28 Aug 2017].

35 Blak BT, Thompson M, Dattani H, et al. Generalisability of the health improvement network (thin) database: demographics, chronic disease prevalence and mortality rates. Inform Prim Care 2011;19:251-5.

36 McGovern A, van Vlymen J, Liyanage $\mathrm{H}$, et al. A simple clinical coding strategy to improve recording of child maltreatment concerns: an audit study. Br J Gen Pract 2014;64:389.3-90. 
37 IQVIA. IQVIA Medical Research Data - Health Research Authority, 2018. Available: https://www.hra.nhs.uk/planning-and-improvingresearch/application-summaries/research-summaries/the-healthimprovement-network-thin-database/

38 Booth N. What are the read codes? Health Libr Rev 1994;11:177-82.

39 Maguire A, Blak BT, Thompson M. The importance of defining periods of complete mortality reporting for research using automated data from primary care. Pharmacoepidemiol Drug Saf 2009;18:76-83.

40 Horsfall L, Walters K, Petersen I. Identifying periods of acceptable computer usage in primary care research databases. Pharmacoepidemiol Drug Saf 2013;22:64-9.

41 Chandan JS, Thomas T, Raza K, et al. Association between child maltreatment and central sensitivity syndromes: a systematic review protocol. BMJ Open 2019;9:e025436.

42 Hughes K, Bellis MA, Hardcastle KA, et al. The effect of multiple adverse childhood experiences on health: a systematic review and meta-analysis. Lancet Public Health 2017;2:e356-66.

43 Department for Education. Children looked after in England including adoption: 2018 to 2019 - GOV.UK, 2019. Available: https://www.gov. uk/government/statistics/children-looked-after-in-england-includingadoption-2018-to-2019 [Accessed 15 Dec 2019].

44 Townsend P, Phillimore P, Beattie A. Health and deprivation: inequality and the North. London: Croom Helm Google Sch, 1988.

45 Public Health England. Public health profiles children subject to a child protection plan with initial category of abuse: rate per 10,000 children aged under 18, 2019. Available: https://fingertips.phe.org.uk/ search/child protection\#page/4/gid/1/pat/6/par/E12000004/ati/102/ are/E06000015/iid/92853/age/173/sex/4 [Accessed 16 Dec 2019].

46 Fahmy E, Emma Williamson CP. Evidence and policy review: domestic violence and poverty, 2016. Available: https://research- information.bris.ac.uk/en/publications/evidence-and-policy-review( af69c4ab-ff0b-4392-9318-890dc0fcc359).html

47 Bywaters P, Bunting L, Davidson G. The relationship between poverty child abuse and neglect: an evidence review, 2016: 74.

48 Owen C, Statham J. Disproportionality in child welfare : the prevalence of black and minority ethnic children within the 'looked after' and 'children in need' populations and on child protection registers in England, 2009. Available: https://www.semanticscholar. org/paper/Disproportionality-in-child-welfare-\%3A-the-of-blackOwen-Statham/c3bec39040bc3816b2bce4cde6e51dc05321996b [Accessed 16 Dec 2019].

49 Gerbert B, Moe J, Caspers N, et al. Simplifying physicians' response to domestic violence. West J Med 2000;172:329-31.

50 National Institute for Health and Care Excellence. Quality and Outcomes Framework Indicators - Standards \& Indicators, 2016. Available: https://www.nice.org.uk/Standards-and-Indicators/ QOFIndicators [Accessed 28 Jul 2019].

51 Gilbert R, Kemp A, Thoburn J, et al. Recognising and responding to child maltreatment. Lancet 2009;373:167-80.

52 Fraser JA, Mathews B, Walsh K, et al. Factors influencing child abuse and neglect recognition and reporting by nurses: a multivariate analysis. Int J Nurs Stud 2010;47:146-53.

53 NSPCC. Giving victims a voice, 2013. Available: https://www.nspcc. org.uk/globalassets/documents/research-reports/yewtree-reportgiving-victims-voice-jimmy-savile.pdf

54 Mathur R, Bhaskaran K, Chaturvedi N, et al. Completeness and usability of ethnicity data in UK-based primary care and hospital databases. J Public Health 2014;36:684-92. 